\title{
Caregiving Education by Medical Students: Are They Prepared to Shoulder Education of the Caregivers?
}

\author{
Fahisham Taib, Surini Yusoff
}

Pediatrics Department, School of Medical Sciences, Universiti Sains Malaysia, Kelantan, MALAYSIA

To cite this article: Taib F, Yusoff S. Caregiving education by medical students: are they prepared to shoulder education of the caregivers? Education in Medicine Journal. 2019;11(4):75-80. https://doi. org/10.21315/eimj2019.11.4.8

To link to this article: https://doi.org/10.21315/eimj2019.11.4.8

\section{ABSTRACT}

The study aims to evaluate the final year medical students' preparedness in providing caregiving information to the future caregivers. A cross-sectional study was completed among the final year medical undergraduate at Universiti Sains Malaysia in Kubang Kerian. Students have been exposed to various community, rehabilitative and palliative care programmes. The purposive sampling method was used, using modified Preparedness for Caregiver Scale (PCS) as the tool in January 2019. A total of 126 students agreed to participate but only 125 have completed the questionnaire given with the response rate of $99.2 \%$. Four students were excluded. This was supported by $30 \%-50 \%$ (scale 3 and 4 ) of the items in the PCS questionnaire were answered by the participated medical students, indicating their readiness towards caregiving education. Our study showed that senior medical students were adequately prepared to work as caregivers in the community. Caregiving skills exposure are important in strengthening students' learning and readiness in disseminating knowledge to other caregivers.

Keywords: Medical students, Caregiving, Education, Caregivers, Preparedness

\section{INTRODUCTION}

Caregiving is a skill whereby sick children or people are looked after in the community. Caregivers are a very diverse group of individuals, with a variety of needs and a wide range of abilities. According to Merriam-Webster online dictionary, caregiver is a person who provides direct care to chronically ill patients (1). Research suggests that caregiver preparedness is essential to minimising the negative impact of caregiving. Not being prepared is associated with fear, anxiety, stress and feeling of insufficiency and uncertainty specific to the caregiver role (2). It is a different skills from what the health care professionals perform on a daily basis. Final year undergraduate students are considered as the senior most trainee due to their exposure to different aspect of skills, knowledge and preparation prior to entry to a full medical employment. Their role in learning is task oriented, and numerous formative and summative assessments are executed to achieve competency in knowledge, skills and attitude. Many studies explored medical students' clinical competency as junior doctors (3-4), but not as a "health educator". Caregiver education 
is vital as part of total patient's care package to improve care at home. Partnering with primary caregivers can provide a balanced understanding of the demands and needs for the comprehensive support in the community.

Caregiving education is aimed to equip caregivers with necessary know-how and limiting negative impact on their health and well-being (5). Community participation in parallel with education and support leads to reduction in cost of care. The use of volunteers and family members has alleviated burden of care provided by the local government. Caregiving educational programme must consider universal needs such as understanding the disease processes, coping skills, problem solving skills and support. Information and knowledge to caregivers of those with particular health problems are done with partnership with local resources. Confidence in palliative caregiving is moderate and many prefer to be trained by the healthcare providers, such as physicians and nurses (6). Many of caregivers learned the caregiving methods via experience and information search through the web.

Education, practical training and mentorship are the essential elements for the success of caregiving education. Undergraduate medical students are exposed to various experiences during their pre-clinical, community and clinical training. This indirectly taught students on caregiving methods and utilising that knowledge to educate others. Our study aims to evaluate the final year medical students' preparedness in providing caregiving information to the future caregivers.

\section{METHODOLOGY}

This is a cross-sectional study using all final year medical undergraduate at Universiti Sains Malaysia in Kubang Kerian. Under the new curriculum, students, who have been exposed to community, rehabilitative and palliative care medicine, acted as "shadow houseman" in training. Students who refused to participate and those grouped as remedial students, were excluded. We used a purposive sampling method to collect data from undergraduate (Year 5) students. The researchers used Preparedness for Caregiver Scale (PCS) which added demographic data and qualitative questionnaires. This allows information regarding the demographic distribution of students' data. The PCS questionnaire was initially sent to the leaders of six groups who then distributed it to all group members. Completed questionnaire were collected by the group leaders, who then returned them back to the researchers. The questionnaire had two sections: first section consisted of demographic information, and the second section was a validated PCS questionnaire in English. A total score ranging from 0 to 32 is calculated by summing the responses from all items, with higher score indicating more preparedness. Internal consistency of this tool has been reported as moderate to high (as 0.88 to 0.93 ). Cronbach alpha was 0.94 and test-retest reliability 0.92 in one study (7-8). The data was collected in January 2019. Descriptive statistics were used to describe students' characteristic and their answers to PCS questionnaire.

\section{RESULT}

A total of 126 participants agreed to participate but only 125 completed the questionnaire (Table 1). Thus, the response rate was $99.2 \%$. Four students were excluded because of remedial students' status. The group consisted of predominantly female students $(66.7 \%)$, single $(99.2 \%)$ and middle class family $(51.6 \%)$. Only $7.1 \%$ of the participants had some experienced of caregiving for their closed relative or family members.

The level of preparedness in our medical students were appropriate and satisfactory 
Table 1: Demographic data of USM final year medical students participated in the study

\begin{tabular}{ll}
\hline Baseline characteristics & N (\%) \\
\hline Age & \\
23 & $29(23)$ \\
24 & $87(69)$ \\
25 & $9(7.1)$ \\
26 & $1(0.8)$ \\
Sex & \\
Male & $42(33.3)$ \\
Female & $84(66.7)$ \\
Ethnicity & \\
Malay & $48(38.1)$ \\
Chinese & $43(34.1)$ \\
Indian & $34(27)$ \\
Others - Melanau & $1(0.8)$ \\
Marital status & \\
Single & $125(99.2)$ \\
Married & $1(0.8)$ \\
Family Income & \\
Less than RM3,900 & \\
Between RM3,900-RM13,000 & $49(38.9)$ \\
Above RM13,000 & $65(51.6)$ \\
Experience to caregiving & $12(9.5)$ \\
Yes & \\
No & $9(7.1)$ \\
Adequate knowledge & $117(92.9)$ \\
Yes & \\
No & \\
Not answered & $70(55.6)$ \\
\hline
\end{tabular}

(Table 2). The study descriptively investigated the perceived readiness of the medical students to caregiving, indirectly their ability to educate of the future caregivers. Although many students have never experienced being the caregivers, most of them were practically prepared in term of knowledge and skills. We found most the items in the PCS questionnaire was answered ranging from $30 \%-50 \%$ (scale 3 \& 4). This was evident in partcipants' reply - Item $1(32 \%)$, Item 2 (33\%), Item $3(38.4 \%)$, Item $4(28.2 \%)$, Item $5(32 \%)$, Item $6(32.8 \%)$, Item $7(51.2 \%)$ and Item $8(40 \%)$. The students believed that they were able to disseminate the information effectively to the future caregivers in the community.

\section{DISCUSSION}

Medical students has been used to administer care and educate community as a part of national medical educational policy during the shortage of doctors (9). These students should have some knowledge to assist in part of teaching, learning and educating the community. Developing the clinical, research and communication skills are the key for future physicians. These allow exposure to teaching of their colleagues, caregivers and patients, at various skill levels (10). Universiti Sains Malaysia (USM) Medical School has long used SPICES model (self-directed, problem-based, integrated, communitybased, electives and spiral learning) as 
Table 2: Preparedness Caregivers Scale (PCS) items answered by the medical students

\begin{tabular}{|c|c|c|c|c|c|c|}
\hline No. & PCS items & $0(\%)$ & $1(\%)$ & $2(\%)$ & $3(\%)$ & $4(\%)$ \\
\hline 1 & $\begin{array}{l}\text { How well prepared do you think you are to take } \\
\text { care of your relative/friend's physical needs? }\end{array}$ & $1(0.8)$ & $21(16.8)$ & $63(50.4)$ & $38(30.4)$ & $2(1.6)$ \\
\hline 2 & $\begin{array}{l}\text { How well prepared do you think you are to take } \\
\text { care of your relative/friend's emotional needs? }\end{array}$ & $3(2.4)$ & 19 (15.2) & $58(46.4)$ & $42(33.6)$ & $3(2.4)$ \\
\hline 3 & $\begin{array}{l}\text { How well prepared do you think you are to } \\
\text { find out about and set up services for your } \\
\text { relative/friend? }\end{array}$ & $0(0)$ & $27(21.3)$ & $50(40)$ & $42(33.6)$ & $6(4.8)$ \\
\hline 4 & $\begin{array}{l}\text { How well prepared do you think you are for } \\
\text { the stress of caregiving? }\end{array}$ & $4(3.2)$ & $37(29.6)$ & $50(40)$ & $32(25.6)$ & $2(1.6)$ \\
\hline 5 & $\begin{array}{l}\text { How well prepared do you think you are to } \\
\text { make caregiving activities pleasant for both } \\
\text { you and your relative/friend? }\end{array}$ & $5(4)$ & $22(17.6)$ & $58(46.4)$ & $37(29.6)$ & $3(2.4)$ \\
\hline 6 & $\begin{array}{l}\text { How well prepared do you think you are to } \\
\text { respond to and handle emergencies that } \\
\text { involve your relative/friend? }\end{array}$ & $5(4)$ & $24(19.2)$ & $55(44)$ & $39(31.2)$ & $2(1.6)$ \\
\hline 7 & $\begin{array}{l}\text { How well prepared do you think you are to } \\
\text { get the help and information you need } \\
\text { from the health care system? }\end{array}$ & $2(1.6)$ & $11(8.8)$ & $48(38.4)$ & 52 (41.6) & $12(9.6)$ \\
\hline \multirow[t]{2}{*}{8} & $\begin{array}{l}\text { Overall, how well prepared do you think } \\
\text { you are to care for your relative/friend? }\end{array}$ & $0(0)$ & $21(16.8)$ & 21 16.8) & $41(32.8)$ & $9(7.2)$ \\
\hline & $\begin{array}{l}0 \text { - Not at all prepared } \\
1 \text { - Not too well prepared } \\
2 \text { - Somewhat well prepared } \\
3 \text { - Pretty well prepared } \\
4 \text { - Very well prepared }\end{array}$ & & & & & \\
\hline
\end{tabular}

part of their educational curriculum. The model relates to educational strategies which represents a continuum learning from teacher-centred to student-centred learning, problem-based and integrated learning, hospital-based to communitybased learning, electives attachment and apprenticeship-based approach in the curriculum planning (11). This has potential exposure at different points in students' learning. During the community posting, students are exposed on various aspect of family, self and community care, following their involvement in the patients' selection for community and social intervention (12). This would enable understanding of social issue and the dynamic behind it. It prepares the medical students with all necessary communication and soft skill tools when imparting education and advice among the caregivers and community as a whole.
Our study showed one third of the medical students in our cohort were prepared to serve as caregivers, indirectly showed their ability to be educator to other caregivers. This certainly has reflected students' maturity, readiness and preparedness towards empowering caregivers. Previous study focused on the principles of teaching in the pediatric setting to all medical care providers, to ensure competent patientcentered care. This includes effective developmental appropriate communication, sharing of information to avoid the feelings of isolation and abandonment, serving the needs of patients, careful recognition, assessment and treatment, forging partnerships with families and addressing personal and professional challenges (13). Teaching of caregiver can be informally done to reduce the negative impact of caregiving and stress. Preparedness to 
caregiving and use that knowledge to educate caregivers can be unique. Feeling of being prepared is influenced by the way caregivers reacted to various caregiving situations. High level of caregivers' preparedness lead to high level of hope and lower anxiety level due to their readiness to face the emotional challenges and care demand. Students' contribution may be vital to fill in the gap of care in our scenario. Despite the readiness of final year students to be the caregiver, unfortunately, there is no legal framework for these students to work as caregivers and educationist, to the other caregivers in the community.

\section{LIMITATIONS OF THE STUDY}

PCS questionnaire previously have been applied to look at caregivers preparedness towards caregiving (14). We investigated medical student preparedness of becoming caregiver, but indirectly reflect their readiness to become health educator as per PCS objectives. Although, the tool have good internal consistency, however this has yet to be tested on medical students population. The second limitation is related to reality of caregiving. Expected skills are different from anticipated one. Medical students may learn skills during their clinical multidisciplinary team attachment and moreover during the community posting. This perhaps help them to understand the challenges of managing chronic patients at home and applying simple skills to the caregivers. Complex skills such as grieving counselling and difficult communication experience may be difficult to apply. We also are aware of the limitation of students in giving advice. This would be related to specific experience by the students and individualised requirement of the patients.

We did not clarified specified skill sets needed in order to becoming a caregiver educationist. The technique of caregiving can be easily obtained from Ministry of Health website and tailored those information according to the needs of each caregiver. Understanding that caregiving skills must be an important part for ongoing education and dissemination of information in the community.

\section{CONCLUSION}

The study showed that senior medical students are prepared to work together with medical teams to impart skills, knowledge as well as a holistic support for the caregivers in the community. Experiential learning during the undergraduate training and exposure towards these caregiving skills help students to strengthen their learning and readiness in disseminating their knowledge to others.

\section{REFERENCES}

1. Conti CR. Doctors are caregivers or providers? Patients are clients? Clin Cardio. 2008;31:505. https://doi.org/10.1002/clc. 20414

2. Williams AM. Education, training, and mentorship of caregivers of Canadians experiencing a life-limiting illness. J Palliat Med. 2017;20(1):45-9. https://doi.org/ $10.1089 /$ jpm.2017.0393

3. Brennan N, Corrigan O, Allard J, Archer J, Barnes R, Bleakley A, et al. The transition from medical student to junior doctor: today's experiences of tomorrow's doctors. Med Educ. 2010;44:449-58. https://doi. org $/ 10.1111 / j .1365-2923.2009 .03604 . x$

4. Burford B, Whittle V, Vance GHS. The relationship between medical student learning opportunities and preparedness for practice: a questionnaire study. BMC Med Educ. 2014;14:223. https://doi. org/10.1186/1472-6920-14-223

5. Chiu MYL, Wei GFW, Lee S, Choovanichvong S, Wong FHT. Empowering caregivers: impact analysis of Familylink Education Programme (FLEP) in Hong Kong, Taipei and Bangkok. Int J Soc Psychiatry. 2011;59(1):28-39. https://doi. org/10.1177/0020764011423171 
6. Hudson PL, Hayman-White K. Measuring the psychosocial characteristics of family caregivers of palliative care patients: psychometric properties of nine selfreport instruments. J Pain Symptom Manage. 2006;31(3):215-28. https://doi. org/10.1016/j.jpainsymman.2005.07.010

7. Henriksson A, Hudson P, Ohlen J, Thomas K, Holm M, Carlander I, Hagell $\mathrm{P}$, Arestedt $\mathrm{K}$. Use of the preparedness for caregiving scale in palliative care: a rasch evaluation study. J Pain Symptom Manage. 2015;50(3):533-41. https://doi. org/10.1016/j.jpainsymman.2015.04.012

8. Pucciarelli G, Savini S, Byun E, Simeone S, Barbaranelli C, Vela RJ, et al. Psychometric properties of caregiver preparedness scale in caregivers of stroke survivors. Heart Lung. 2014;43(6):555-60. https://doi. org/10.1016/j.hrtlng.2014.08.004

9. Mortelmans LJM, De Cauwer HG, Van Dyck E, Monballyu P, Van Giel R,Van Turnhout E. Are Belgian senior medical students ready to deliver basic medical care in case of a H5N1 pandemic? Prehosp Disaster Med. 2009;24(5):438-42. https:// doi.org/10.1017/S1049023X00007287
10. Peluso MJ, Hafler JP. Medical students as medical educators: opportunities for skill development in the absence of formal training programs. Yale J Biol Med. 2011;84(3):203-9.

11. Azila NMA, Jaafar R, Mohd Hussin ZA. Curricular trends in Malaysian medical schools: innovations within. Ann Acad Med Singapore. 2006;35:647-54.

12. Taib F, Mohd Fakri NMR. Revitalizing community and family case study (CFCS) programme. Education in Medicine Journal. 2014;6(3):46-50. https://doi.org/10.5959/ eimj.v6i3.260

13. Sahler OJZ, Frager G, Levetown M, Cohn FG, Lipson MA. Medical education about end-of-life care in the pediatric setting: principles, challenges, and opportunities. Pediatrics. 2000;105:575-84. https://doi. org/10.1542/peds.105.3.575

14. Carter JH, Stewart BJ, Archbold PG, Inoue I, Jaglin J, Lannon M, et al. Living with a person who has Parkinson's disease: the spouse's perspective by stage of disease. Move Disord. 1998;13(1):20-8. https://doi. org/10.1002/mds.870130108 